\title{
Unusual Manifestation of Gastric Helicobacter pylori Infection
}

\author{
Amit K. Dutta ${ }^{a, c}$ Toshimi Chiba $^{a}$ Yosuke Toya $^{a}$ \\ Tomomi Mizutani $^{a}$ Satoshi Kasugai ${ }^{a} \quad$ Nozomi Matsuda ${ }^{a}$ \\ Sho Shibata ${ }^{a}$ Yukito Abiko $^{\text {a }}$ Risaburo Akasaka ${ }^{a}$ \\ Naoki Yokoyama ${ }^{a}$ Shuhei Oana ${ }^{a}$ Shigeru Hirota ${ }^{a}$ \\ Masaki Endo ${ }^{a}$ Noriyuki Uesugi ${ }^{b}$ Tamotsu Sugai ${ }^{b}$ \\ Kazuyuki Suzuki ${ }^{\mathrm{a}}$ \\ ${ }^{a}$ Division of Gastroenterology and Hepatology, Department of Internal \\ Medicine, and ${ }^{b}$ Division of Molecular Diagnostic Pathology, Department of \\ Pathology, School of Medicine, Iwate Medical University, Morioka, Japan; \\ ${ }^{\mathrm{C}}$ Department of Gastroenterology, Christian Medical College and Hospital, \\ Vellore, India
}

\section{Key Words}

Helicobacter pylori · Hypertrophic gastropathy · Differential diagnosis

\begin{abstract}
Infection with Helicobacter pylori (HP) is common in many parts of the world. While most patients are asymptomatic, it causes peptic ulcer disease and malignancy in some of them. Other rare conditions have occasionally been reported in association with this infection. We report a case of hypertrophic gastropathy caused by HP in a 52-year-old asymptomatic patient. He was found to have marked enlargement of the gastric mucosal folds on radiological imaging and endoscopy. A gastric mucosal biopsy showed HP colonization associated with neutrophilic inflammation. After exclusion of neoplasia, other infections and infiltrative disorders, HP was thought to be the cause of the gastric fold hypertrophy. The patient responded well to HP eradication therapy, with normalization of the gastric mucosal folds. HP infection should be considered in the differential diagnosis of hypertrophic gastropathy and treated accordingly.
\end{abstract}




\section{Introduction}

The mucosal folds in the body of the stomach are usually less than $1 \mathrm{~cm}$ thick [1]. Occasionally these folds, also referred to as rugae, may thicken and enlarge, a condition known as hypertrophic gastropathy. While Ménétrier's disease is most commonly associated with hypertrophic gastric folds, a variety of other diseases have also been associated [2]. These include Zollinger-Ellison syndrome, gastric lymphoma, diffuse gastric cancer, polyposis and eosinophilic gastroenteritis [2]. Rarely, infections with human cytomegalovirus (CMV) or Helicobacter pylori (HP) may cause enlargement of the gastric folds [3, 4]. Although awareness of these mimics of Ménétrier's disease is crucial, it may have an important bearing on patient management and outcome. We report a patient with hypertrophic gastropathy caused by $H P$ who showed dramatic response to therapy.

\section{Case Report}

A 52-year-old man undergoing screening for gastric cancer was found to have grossly enlarged gastric mucosal folds (fig. 1a) on barium examination of the stomach. He was referred to our institution for further evaluation. There was no history of upper abdominal pain, vomiting, anorexia or significant weight loss. Laboratory testing revealed hemoglobin $15.1 \mathrm{~g} / \mathrm{dl}$, total protein $6 \mathrm{~g} / \mathrm{dl}$, serum albumin $3.9 \mathrm{~g} / \mathrm{dl}$, total leucocyte count $9,320 / \mu \mathrm{l}$, eosinophils $5.8 \%$, serum gastrin $87 \mathrm{IU} / \mathrm{ml}$ and lactate dehydrogenase $155 \mathrm{U} / \mathrm{l}$. Upper gastrointestinal endoscopy showed marked thickening of the gastric folds in the gastric proximal body (fig. 1b). The mucosal surface was not ulcerated. The distal body and antrum appeared normal. Contrast-enhanced computed tomography (CECT) was performed mainly to investigate if other intra-abdominal lesions such as neuroendocrine tumor, lymphadenopathy or metastatic disease might be responsible for the thickened gastric folds. Except for the thickened upper body of the stomach, no other lesions were revealed (fig. 1c, d). Endoscopic ultrasonography (EUS) was performed to determine the origin of the thickened gastric mucosal folds and whether the layers of the gastric wall were preserved. EUS showed that the thickening in the proximal body was confined to the mucosal layer and that the muscularis propria and serosal layers were normal. Whole-body gallium scan for the presence of neoplastic lesions was normal. Since gastric lymphoma, especially mucosa-associated lymphoid tissue lymphoma, was considered in the differential diagnosis, the interleukin 2 receptor serum level was measured and found to be mildly elevated at $783 \mathrm{U} / \mathrm{ml}($ normal $<520 \mathrm{U} / \mathrm{ml})$.

Gastric mucosal biopsies were performed during gastroscopy. Histological examination revealed numerous $H P$ organisms on Giemsa staining (fig. 2 a). Significant neutrophilic infiltration was seen in the mucosa, and there was no evidence of malignancy or CMV infection (fig. 2b). There was also corkscrew-shaped enlargement of the gastric glands. The ratio of gastric crypts to glands was not determined because that assessment required a deeper biopsy. The absence of symptoms and the finding of normal serum albumin indicated that Ménétrier's disease was unlikely, and the diagnosis of hypertrophic gastropathy associated with $H P$ infection was considered.

The patient received $H P$ eradication therapy consisting of 1 week of treatment using lansoprazole, amoxicillin and clarithromycin. He underwent a barium examination 5 months later, which revealed normal gastric mucosal folds (ig. 3 a). Gastroscopy showed that the thickened gastric mucosal folds previously seen in the proximal body were normal (fig. 3b, c). A repeat mucosal biopsy was negative for HP organisms, and the neutrophilic infiltration seen on the initial biopsy was minimal (fig. 3d).

\section{Discussion}

Infection with $H P$ is common, with about half of the world's population harboring this bacterium in their stomach [5]. The infection is asymptomatic in most individuals. 
Since $H P$ infection is associated with important clinical diseases such as peptic ulcer disease, gastric lymphoma and gastric carcinoma, therapy is warranted for its eradication. Other conditions sometimes linked with $H P$ infection include idiopathic thrombocytopenic purpura, iron deficiency anemia, scleroderma, idiopathic urticaria and migraine [6]. Eradication therapy is generally recommended only for idiopathic thrombocytopenic purpura and unexplained iron deficiency anemia because evidence for association with $H P$ is weak for the other conditions [7]. Recently, hypertrophic gastropathy associated with $H P$ has been proposed as an indication for treatment [8]. The dramatic improvement in gastric fold morphology and histology that was seen after eradication therapy in our patient provides additional support that patients with $H P$-associated hypertrophic gastropathy should be treated. These patients may be at increased risk of gastric cancer, which underlines the importance of prompt treatment [9].

Since hypertrophic gastric mucosal folds can be associated with many conditions, a thorough clinical and diagnostic evaluation is required to exclude other causes. Patients with Ménétrier's disease are usually symptomatic and present with epigastric pain, vomiting, weight loss and low serum albumin level as a result of loss of proteins from the stomach [10]. Patients with lymphoma and carcinoma commonly have anorexia and weight loss. In patients with Zollinger-Ellison syndrome, the serum gastrin levels may be very high, multiple ulcers may be seen on gastroduodenoscopy, and abdominal imaging may show a tumor. Hence, serum albumin level, total and differential leukocyte count (eosinophilia in hypereosinophilic disorders), serum gastrin level, CMV serology and abdominal imaging (CECT, EUS) play an important role in the evaluation of patients with hypertrophic gastropathy [2]. Our patient was asymptomatic, had a normal serum albumin and was tumor-free on imaging, which indicated that the conditions considered in the differential diagnosis were less likely.

The definitive diagnosis is derived from histological examination of the gastric mucosa, and therefore biopsy, preferably using a sufficiently large forceps to obtain a deep sample, is crucial [2]. Ménétrier's disease is characterized by foveolar hyperplasia and scanty parietal cells, lymphoma and carcinomas manifest infiltration by neoplastic cells, inclusion bodies may be seen with CMV infection, and eosinophilic gastroenteritis shows infiltration with eosinophils [10]. Evidence of $H P$ infection by itself may not be sufficient to establish a cause-effect relationship with hypertrophic gastric folds. The significant neutrophilic infiltration of the mucosa, exclusion of other causes and the resolution of thickened gastric mucosal folds and inflammation after bacterial eradication therapy in our patient strongly suggested that $H P$ was the cause of his hypertrophic gastropathy. There are also a few case reports describing the association of $H P$ with lymphocytic and granulomatous gastritis, indicating that $H P$ can cause non-neoplastic enlarged gastric folds [11,12].

The mechanism of gastric fold enlargement associated with HP infection is unclear. Bacterial components may induce a distinct cytokine profile that may promote cellular proliferation and enlargement of the gastric folds. One report suggested that increased production of interleukin-1 beta and hepatocyte growth factor during HP infection may result in gastric fold thickening [13]. The mutagenicity of gastric juice is increased in patients with $H P$ infection and enlarged gastric folds, which may explain the increased risk of cancer in these patients [9]. 


\begin{tabular}{r|l|l|l}
$\begin{array}{r}\text { Case Reports in } \\
\text { Gastroenterology }\end{array}$ & $\begin{array}{l}\text { Case Rep Gastroenterol 2012;6:465-471 } \\
\text { DOI: 10.1159/000341511 }\end{array}$ & $\begin{array}{l}\text { Published online: } \\
\text { July 12, 2012 }\end{array}$ & $\begin{array}{l}\text { @ 2012 S. Karger AG, Basel } \\
\text { ISSN 1662-0631 } \\
\text { www.karger.com/crg }\end{array}$ \\
\hline
\end{tabular}

In conclusion, $H P$ infection should be considered in the differential diagnosis of patients with hypertrophic gastropathy because the infection is easy to treat and the outcome is gratifying.

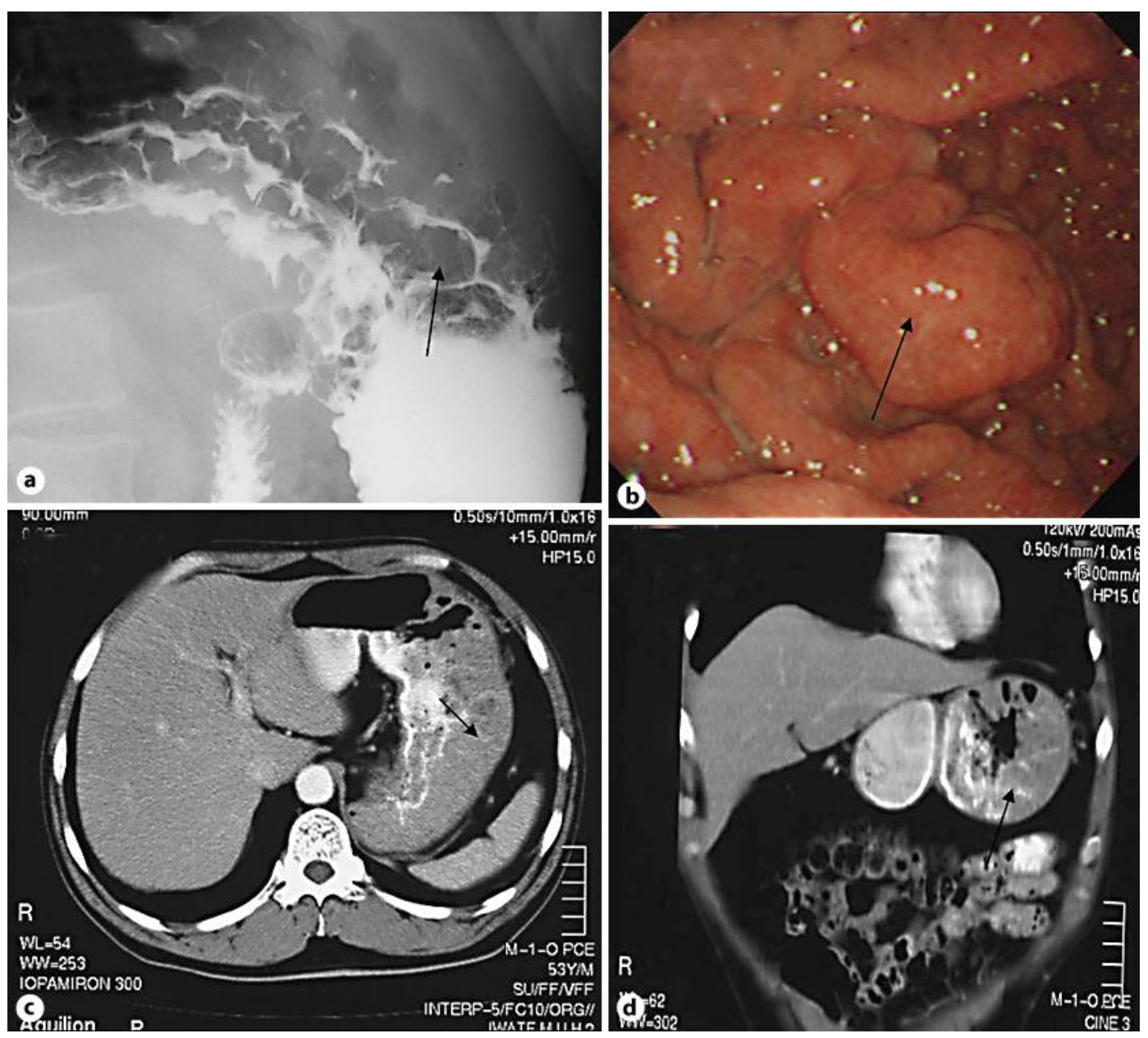

Fig. 1. a Barium study showing thickened gastric folds (arrow). b Marked thickening of the mucosal folds (arrow) in the proximal body of the stomach was seen during gastroscopy. $\mathbf{c}, \mathbf{d}$ Abdominal CECT showed a thickened gastric wall (arrows). 

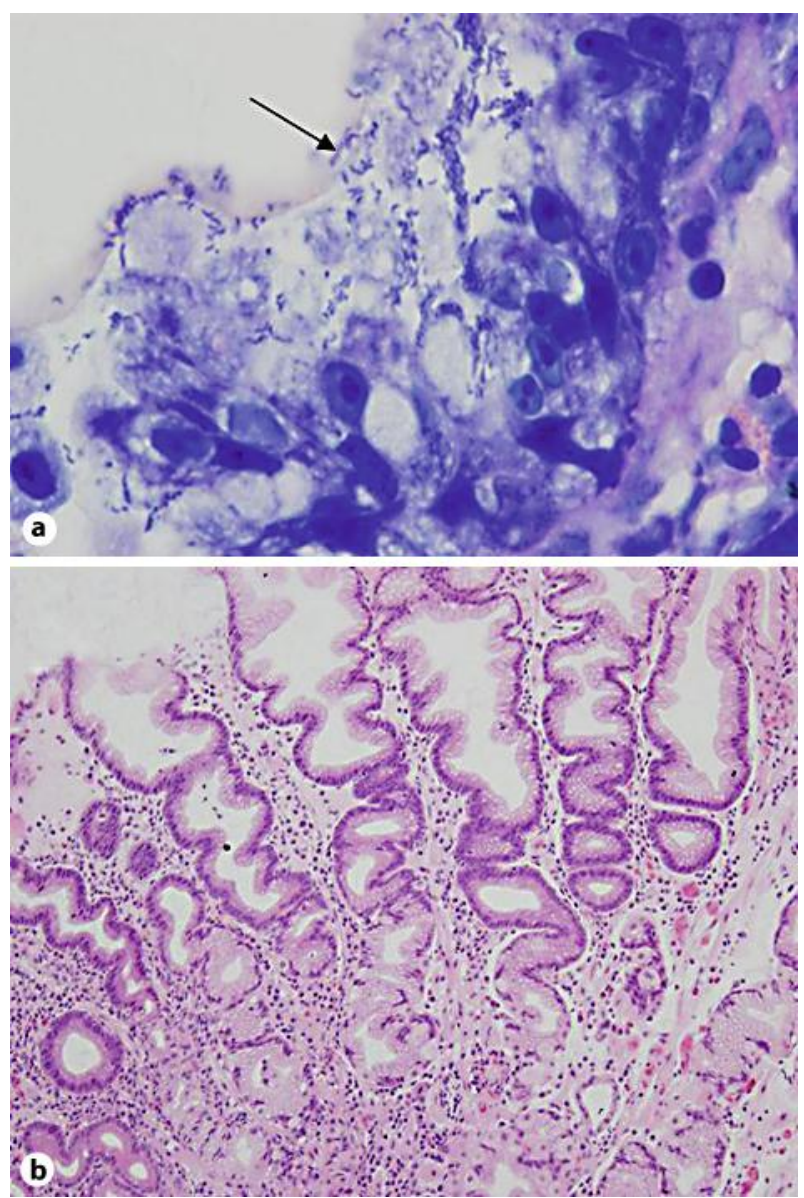

Fig. 2. a Gastric mucosal biopsy showing numerous $H P$ organisms (arrow) on Giemsa staining $(\times 1,000)$. b Gastric mucosal biopsy showing neutrophilic inflammation, corkscrew-shaped enlargement of glands and absence of neoplastic cells on hematoxylin and eosin staining $(\times 100)$. 


\begin{tabular}{r|l|l|l}
$\begin{array}{r}\text { Case Reports in } \\
\text { Gastroenterology }\end{array}$ & $\begin{array}{l}\text { Case Rep Gastroenterol 2012;6:465-471 } \\
\text { DOI: 10.1159/000341511 }\end{array}$ & $\begin{array}{l}\text { Published online: } \\
\text { July 12, 2012 }\end{array}$ & $\begin{array}{l}\text { @ 2012 S. Karger AG, Basel } \\
\text { ISSN 1662-0631 } \\
\text { www.karger.com/crg }\end{array}$ \\
\hline
\end{tabular}
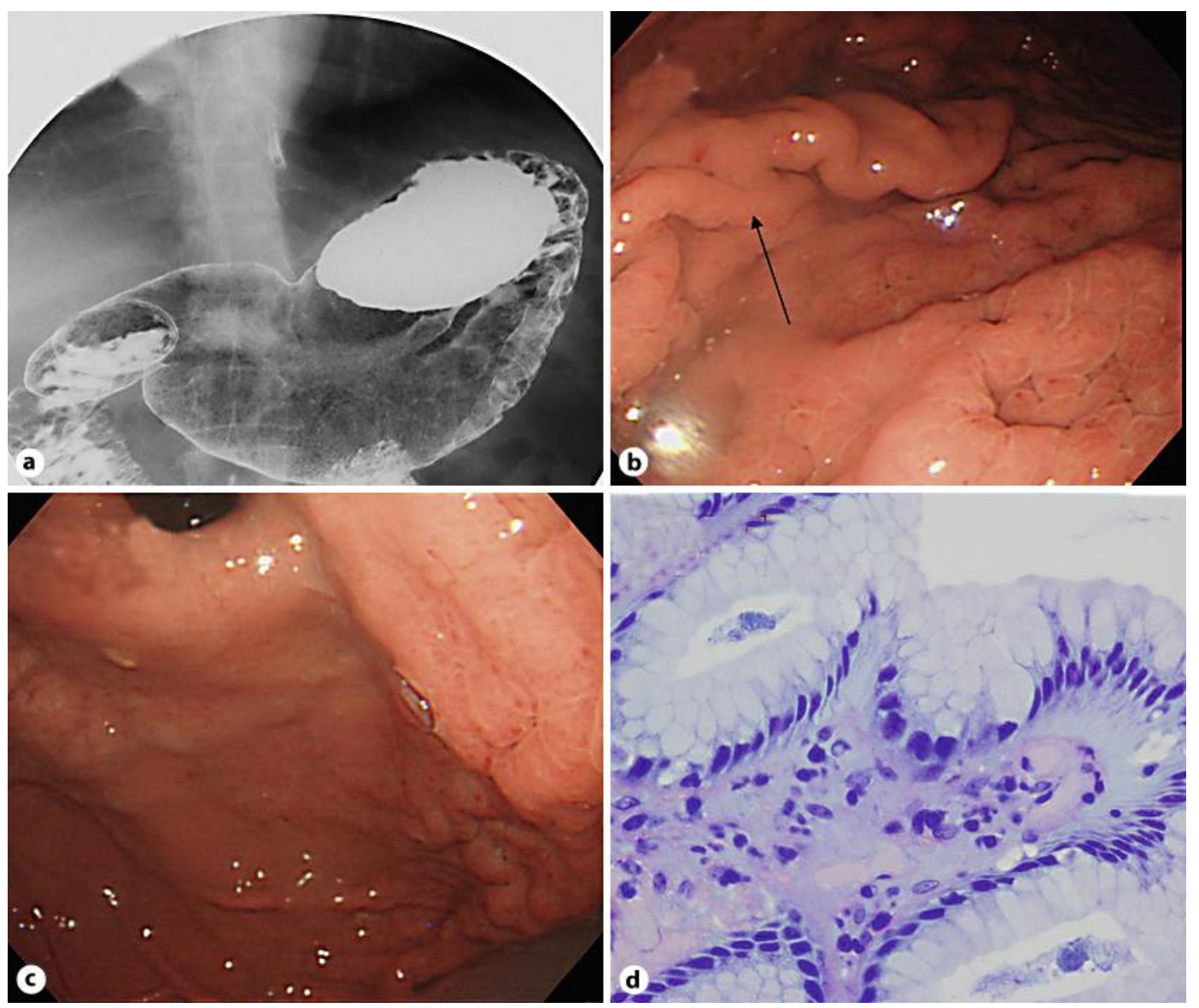

Fig. 3. Findings on gastroscopy, barium study and histologic examination after $H P$ eradication therapy. a Barium examination showing normal stomach. b, c Normal gastric folds (arrow) on gastroscopy. d Gastric mucosal biopsy showing absence of $H P$ organisms on Giemsa staining $(\times 400)$.

\section{References}

1 Bjork JT, Geenen JE, Soergel KH, Parker HW, Leinicke JA, Komorowski RA: Endoscopic evaluation of large gastric folds: a comparison of biopsy techniques. Gastrointest Endosc 1977;24:22-23.

-2 Rich A, Toro TZ, Tanksley J, et al: Distinguishing Ménétrier's disease from its mimics. Gut 2010;59: 1617-1624.

-3 Suter WR, Neuweiler J, Borovicka J, Binek J, Fantin AC, Meyenberger C: Cytomegalovirus-induced transient protein-losing hypertrophic gastropathy in an immunocompetent adult. Digestion 2000;62:276-279.

4 Madsen LG, Taskiran M, Madsen JL, Bytzer P: Ménétrier's disease and Helicobacter pylori: normalization of gastrointestinal protein loss after eradication therapy. Dig Dis Sci 1999;44:2307-2312.

-5 Brown LM: Helicobacter pylori: epidemiology and routes of transmission. Epidemiol Rev 2000;22: 283-297.

6 Figura N, Franceschi F, Santucci A, Bernardini G, Gasbarrini G, Gasbarrini A: Extragastric manifestations of Helicobacter pylori infection. Helicobacter 2010;15(suppl 1):60-68.

$\checkmark 7$ Malfertheiner P, Megraud F, O'Morain C, et al: Current concepts in the management of Helicobacter pylori infection: the Maastricht III Consensus Report. Gut 2007;56:772-781.

8 Lee SY: Future candidates for indications of Helicobacter pylori eradication: do the indications need to be revised? J Gastroenterol Hepatol 2012;27:200-211. 
-9 Nishibayashi H, Kanayama S, Kiyohara T, et al: Helicobacter pylori-induced enlarged-fold gastritis is associated with increased mutagenicity of gastric juice, increased oxidative DNA damage, and an increased risk of gastric carcinoma. J Gastroenterol Hepatol 2003;18:1384-1391.

10 Lambrecht NW: Ménétrier's disease of the stomach: a clinical challenge. Curr Gastroenterol Rep 2011;13:513-517.

11 Madisch A, Aust D, Morgner A, et al: Resolution of gastrointestinal protein loss after Helicobacter pylori eradication in a patient with hypertrophic lymphocytic gastritis. Helicobacter 2004;9:629-631.

12 Kim YS, Lee HK, Kim JO, et al: A case of H. pylori-associated granulomatous gastritis with hypertrophic gastropathy. Gut Liver 2009;3:137-140.

13 Yasunaga Y, Shinomura Y, Kanayama S, et al: Increased production of interleukin 1 beta and hepatocyte growth factor may contribute to foveolar hyperplasia in enlarged fold gastritis. Gut 1996;39:787-794. 